\title{
FLOW BOILING IN MINICHANNELS
}

\author{
André Bontemps ${ }^{(1,2)}$, BRUno AgOstini $^{(3)}$, NADiA CANEY $^{(1,2)}$
}

(1) CEA-GRETh, 17 rue des Martyrs, 38054 Grenoble, France, (2) LEGI/GRETh, Université Joseph Fourier, 17 rue des Martyrs, 38054 Grenoble, France, (3) 15 rue Denis Papin, 38000 Grenoble, France

\section{Introduction}

The use of mini-channel heat exchangers (hydraulic diameter about $1 \mathrm{~mm}$ ) in compact heat exchangers improves heat transfer coefficients, and thermal efficiency while requiring a lower fluid mass. They are widely used in condensers for automobile air-conditioning and are now being used in evaporators, as well as in other applications such as domestic air-conditioning systems. However, more general use requires a better understanding of boiling heat transfer in confined spaces. Many definitions of micro and minichannel hydraulic diameter are used throughout the literature. Kandlikar and Grande (2003) proposed the following classification: conventional channels $\left(D_{\mathrm{h}}>3 \mathrm{~mm}\right)$, minichannels $\left(200 \mu \mathrm{m}<D_{\mathrm{h}}<3 \mathrm{~mm}\right)$, micro-channels $\left(D_{\mathrm{h}}<200 \mu \mathrm{m}\right)$, that will be used throughout this paper.

These definitions rely upon the molecular mean free path in a single-phase flow, surface tension effects and flow patterns in two-phase flow applications. In recent studies in minichannels the hydraulic diameter ranges from $100 \mu \mathrm{m}$ to $2-3 \mathrm{~mm}$. The channel cross sections were either circular or rectangular and much of the research concerned boiling. Commonly, classical correlations have been used with or without modifications to predict flow boiling results in minichannels. However agreement was poor and the need for new correlations was evident.

It has been shown through a number of experiments that boiling is controlled by two additive components: nucleate boiling and convective boiling. Nucleate boiling is due to nucleating bubbles and their subsequent growth and removal from the heated surface. Convective boiling is due to heated fluid moving from the heated surface to the flow core. These two mechanisms cannot be separated with any precision since they are closely interconnected. Figure 1 shows a classical representation of flow boiling regimes in tubes. The successive steps, as the fluid is heated, are:

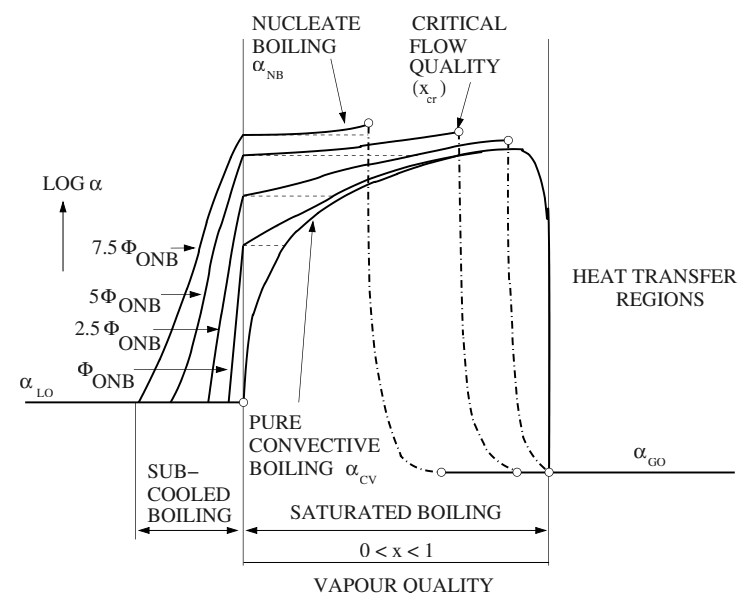

Figure 1: Boiling regimes from Collier and Thome (1994).

(i) In subcooled boiling the average fluid temperature is below the saturation temperature while the fluid at the tube wall has already reached it and therefore can boil. The heat transfer coefficient rises and depends on the heat flux, until the core of the flow, which is colder, reaches the saturation temperature. Bubbles formed at 
the wall move and condense in the flow core and increase its temperature.

(ii) In saturated boiling the flow core has reached saturation. Nucleate and convective boiling compete. In nucleate boiling the heat transfer coefficient depends on the heat flux which is the driving force of bubble generation (dashed lines). In convective boiling the heat transfer coefficient is independent of the heat flux but depends on the liquid quality and mass velocity which are the driving forces of convection. The combination of both shows almost horizontal and parallel lines at low vapour quality (nucleate boiling) which merge into a single increasing line at higher vapour quality (convective boiling). The smaller the heat flux the sooner (in terms of vapour quality) convective boiling will take over from nucleate boiling. This is further highlighted by figure 2 which represents experimental results on flow boiling regimes in tubes.

(iii) At high quality and heat flux, dry-out can occur. This is a dramatic outcome of boiling. The liquid layer wetting the wall and providing heat transportation is totally vaporised. Only gas remains which severely decreases the heat transfer from the wall. With imposed heat flux this can lead to tube meltdown.

(iv) Finally, when all the liquid is vaporised, single-phase gaseous flow governs the heat transfer with, of course, a heat transfer coefficient smaller than for a single-phase liquid flow.

The main difficulty is to establish the dependence of the heat transfer coefficient on vapour quality in relation to different mechanisms controlling flow boiling. Some correlations do not take into account the two mechanisms. Others account for convective and nucleate boiling. To the present author's knowledge, none take into account the influence of channel size. The aim here is to summarise recent work on flow boiling, to describe an experiment on the phenomenon in minichannels and to compare the results with classical correlations.

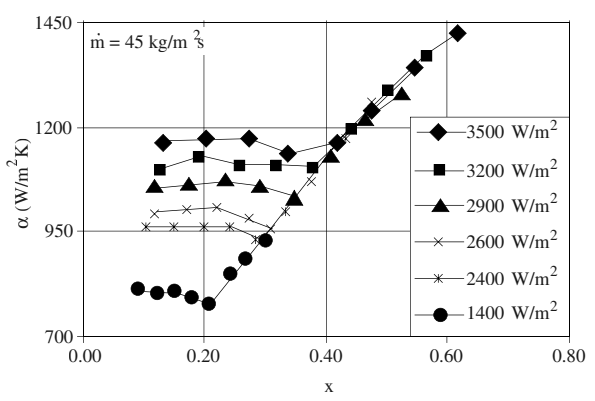

Figure 2: Boiling regimes observed Feldman (1996).

\section{Review of selected flow boiling correlations for minichannels}

For an extended review of experimental work on mini and microchannels, the reader is refered to the Thome (2004) and Kandlikar (2002) papers. This brief review covers a representative selection of heat transfer studies in minichannels and its aim is to illustrate the tendencies observed in the presented data. Recently Kandlikar (2004) developed a new general correlation adapted to minichannels which gives very good results for low qualities but fails to take dry-out into account, as noted by the author in question. Lately Thome et al. (2004) and Dupont et al. (2004) proposed a semi-empirical three zone model which is the only published work to predict the unique trends observed in minichannels. In this model the dominant boiling mechanism is the evaporation of the liquid film pressed under confined bubbles.

A few studies on boiling in minichannels are available in the literature. The experimental conditions are gathered in table 1. Tran et al. (1997), Aritomi et al. (1993) and Kew and Cornwell (1997) established correlations of heat transfer coefficient for various refrigerants. All noted that the local heat transfer coefficient was only dependent on the heat flux. Accordingly they concluded that the governing mechanism was nucleate boiling and no dependence on quality was considered. Recently, Huo et al. (2004) studied boiling of refrigerant R134a in minichannels and highlighted the prevalence of nucleate boiling and the occurrence of dry-out at low vapour quality. Kew and Cornwell (1997) defined a non dimensional confinement number, Co, and proposed that microscale boiling should prevail for $\mathrm{Co}>0.5$ while macroscale boiling would occur for $\mathrm{Co}<0.5$. 
However some experimental studies in similar geometries show a dependence of the heat transfer coefficient on vapour quality. The Feldman (1996), Oh et al. (1998) and Kandlikar and Grande (2003) correlations illustrate a clear evolution of the heat transfer coefficient with vapour quality. These works indicate that nucleate boiling may not be the only mechanism governing boiling in minichannels and that new mechanisms may happen too.

Table 1: Summary of experimental conditions of some studies on refrigerants flow boiling in minichannels

\begin{tabular}{llllll}
\hline Author & Fluid & $\dot{q}\left(\mathrm{~kW} / \mathrm{m}^{2}\right)$ & $\dot{m}\left(\mathrm{~kg} / \mathrm{m}^{2} \mathrm{~s}\right)$ & $x_{\mathrm{o}}$ & $D_{\mathrm{h}}(\mathrm{mm})$ \\
\hline Aritomi et al. $(1993)$ & $\mathrm{R} 113$ & $10-100$ & $31-620$ & $0-0.8$ & $1-4$ \\
Feldman (1996) & $\mathrm{R} 114$ & $1.4-3.5$ & $20-45$ & $0.1-0.6$ & $1.66-2.06$ \\
Kew and Cornwell (1997) & $\mathrm{R} 113,141 \mathrm{~b}$ & $9.7-90$ & $188-212$ & $0-0.8$ & $1.04-3.69$ \\
Tran et al. $(1997)$ & $\mathrm{R} 12,113,134 \mathrm{a}$ & $0.75-129$ & $44-832$ & $0.2-0.8$ & $2.46-2.92$ \\
Oh et al. (1998) & $\mathrm{R} 134 \mathrm{a}$ & $10-20$ & $240-720$ & $0-1$ & $1-2$ \\
Huo et al. (2004) & $\mathrm{R} 134 \mathrm{a}$ & $13-150$ & $100-500$ & $0-0.9$ & $2.01-4.26$ \\
Present study (2004) & $\mathrm{R} 134 \mathrm{a}$ & $2.8-31.6$ & $90-469$ & $0-1$ & $0.77-2.01$ \\
\hline
\end{tabular}

Another phenomenon experimentally identified in flow boiling is the oscillatory nature of the flow. Some intermittent local dry-out can occur in confined spaces. This occurrence certainly influences the evolution of the heat transfer coefficient at high vapour quality. Brutin et al. (2003) experimentally investigated two-phase flow instabilities in narrow channels. They observed vapour slug formation blocking the two-phase flow and pushing it back to the inlet. Kandlikar and Grande (2003) observed periodic slug flow with quick dry-out and re-wetting. This phenomenon occurs faster and lingers longer when the heat flux increases. However the exact influence on the heat transfer coefficient has not been quantified yet.

Consequently there is no clear indication that boiling phenomena in small diameter channels is either dominated by nucleate boiling or convective boiling or any new mechanism. Yet there is strong evidence that these mechanisms are not interconnected as in conventional tubes. The motivation for the present work is therefore to get a more accurate vision of boiling in minichannels, to establish a correlation for flow boiling in minichannels and consequently to identify the most adapted correlation in the literature. To this end, experimental results of ascendant boiling flow of refrigerant R134a obtained with two minichannels, whose hydraulic diameters are 2 $\mathrm{mm}$ and $0.77 \mathrm{~mm}$, will be presented and discussed.

\section{Experimental set-up}

Figure 3 is a schematic of the R134a experimental facility and test section. The test loop included a liquid pump and a mixed glycol-water circuit for heat evacuation. Subcooled liquid enters the bottom inlet manifold, is then vaporised in the test section and condensed further on in the heat exchanger. The test section consisted of a vertical industrial MPE (MultiPort Extruded) aluminium tube composed of parallel rectangular channels. The whole test section was thermally insulated with wrapping foam. For heat transfer measurements, a section of the tube was heated by Joule effect with the passage of an electric current from two brased electrodes through the tube wall. Upstream of the heated region there was an adiabatic zone to ensure the flow was hydrodynamically developed. Experimental conditions are summarised in table 2.

The determination of the channel dimensions was carried out using scanning electron microscopy. The hydraulic diameter was calculated with the total flow area and wet perimeter measured from electron microscope images in order to take into account the effect of the first and last channels which are rounded. Roughness measurements were also carried-out.

Figure 3 shows the test section and instrumentation. Ten wall temperatures on the tube external surface were measured with $0.5 \mathrm{~mm}$ diameter calibrated type E thermocouples electrically insulated from the aluminium. Fluid inlet and outlet temperatures were measured with $1 \mathrm{~mm}$ diameter calibrated type $\mathrm{K}$ thermocouples. Calibration was carried out with a Rosemount 162-CE platinum thermometer. Due to the high thermal conductivity of the aluminium and the low thickness of the tube walls the measured temperature is very close to the wall temperature in contact with the fluid (the difference less than $0.01 \mathrm{~K}$ ). The inlet fluid pressure was measured with a calibrated Rosemount type II absolute pressure sensor. Two calibrated differential pressure sensors measured the pressure loss through the test section. A Rosemount Micro-motion coriolis flowmeter was used to 
measure the mass flow rate of R134a downstream of the pump. The heating voltage and current were measured directly through a HP 3421A multiplexer. The overall system was tested with single-phase flow runs in order to check heat losses (Agostini et al. (2002) and Agostini (2002)). Classical turbulent single-phase flow correlations agreed with measurements to within $\pm 10 \%$.

The heat flux was varied for every fixed mass flow rate in order to obtain a series of outlet vapour qualities between 0.2 and 1 with a step of 0.05. Steady state values were monitored using a Hewlett Packard 3421A with a 30 minutes time lapse between each mass flow rate or heat flux change. Averaging was carried out after every 20 values and uncertainties were calculated according to the Kline and McClintock (1953) method. The total electrical power dissipated in the test section was calculated as the product of voltage and current. The variations of R134a thermophysical properties with temperature were calculated with the REFPROP 6.01 software.

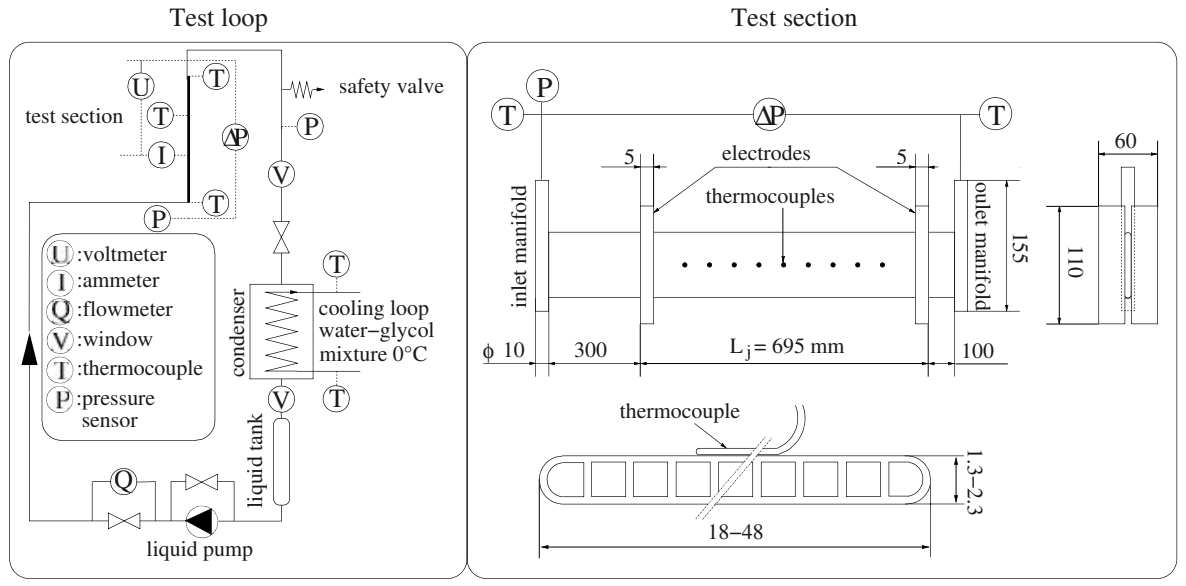

Figure 3: Test loop and test section.

Table 2: Operating conditions and uncertainties

\begin{tabular}{lll|ll}
\hline & value & error & value & error \\
\hline$D_{\mathrm{h}}(\mathrm{mm})$ & 2.01 & $\pm 3 \%$ & 0.77 & $\pm 7 \%$ \\
$\dot{m}\left(\mathrm{~kg} / \mathrm{m}^{2} \mathrm{~s}\right)$ & $90-295$ & $\pm 1.7-8.6 \%$ & $214-469$ & $\pm 3.3-8.6 \%$ \\
$\dot{q}\left(\mathrm{~kW} / \mathrm{m}^{2}\right)$ & $6-31.6$ & $\pm 2-4.1 \%$ & $2.8-19.5$ & $\pm 3 \%$ \\
$T_{\mathrm{w}}, T_{\mathrm{fl}}(\mathrm{K})$ & $276-308$ & $\pm 0.1-3 \mathrm{~K}$ & $281-307$ & $\pm 0.2-2 \%$ \\
$p_{\mathrm{i}}(\mathrm{kPa})$ & $405 \& 608$ & $\pm 4 \%$ & 517 & $\pm 2.7 \%$ \\
$\Delta p(\mathrm{kPa})$ & $9.5-37.5$ & $\pm 1.2-17 \%$ & $153-1570$ & $\pm 0.3-3.7 \%$ \\
\hline
\end{tabular}

\section{Heat transfer results}

In this section the general trends of the measurements will be presented. Electrical power, refrigerant mass flow rate, in and outward fluid temperatures and wall temperatures were measured. From these data physical parameters of interest were computed as a function of tube length: heat flux $\dot{q}(z)$, fluid temperature $T_{\mathrm{fl}}(z)$, vapour quality $x(z)$ and heat transfer coefficient $\alpha(z)$. Table 3 presents uncertainties on some calculated parameters.

Figures 4 and 5 show the local heat transfer coefficient as a function of local quality for $D_{\mathrm{h}}=2 \mathrm{~mm}$ and $D_{\mathrm{h}}=0.77 \mathrm{~mm}$. Two general trends are observed. On figure 4 a strong decrease in the heat transfer coefficient with vapour quality is visible when the vapour quality is greater than a "critical quality" whereas on figure 5 the heat transfer coefficient starts decreasing before increasing with vapour quality. 
Table 3: Uncertainties on calculated parameters

\begin{tabular}{lll|ll}
\hline & value & error & value & error \\
\hline Co & 0.46 & $\pm 3 \%$ & 1.14 & $\pm 7 \%$ \\
Bo $\times 10^{-4}$ & $2.2-7.9$ & $\pm 3.7-10.4 \%$ & $0.7-2.2$ & $\pm 6.3-11.6 \%$ \\
$\alpha\left(\mathrm{kW} / \mathrm{m}^{2} \mathrm{~K}\right)$ & $0.8-10.3$ & $\pm 6-30 \%$ & $0.6-32.5$ & $\pm 5-30 \%$ \\
$x_{\mathrm{o}}$ & $0.26-1$ & $\pm 1-7 \%$ & $0.23-0.9$ & $\pm 2-9 \%$ \\
\hline
\end{tabular}
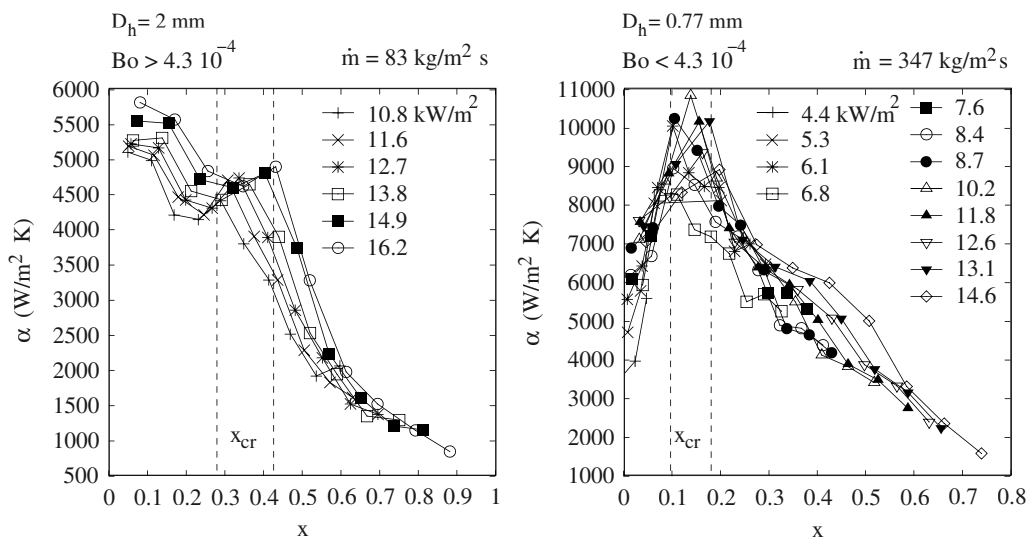

Figure 4: Local heat transfer coefficient versus local quality.

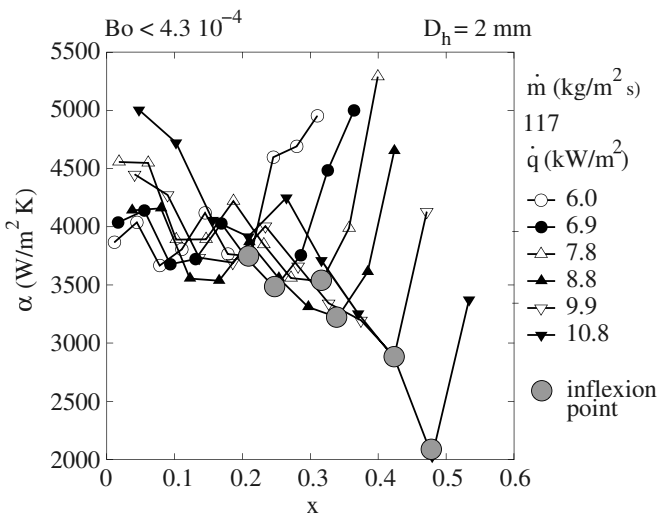

Figure 5: Heat transfer coefficient versus Boiling number $\left(D_{\mathrm{h}}=2 \mathrm{~mm}\right)$. 
Figure 6 shows the local heat transfer coefficient as a function of local quality, for a given heat flux and mass velocity, for $D_{\mathrm{h}}=2 \mathrm{~mm}$ and $D_{\mathrm{h}}=0.77 \mathrm{~mm}$. It is clear that the heat transfer coefficient increases when the hydraulic diameter decreases. Thus the local heat transfer coefficient is increased by $74 \% \pm 26 \%$ when the hydraulic diameter is decreased by $62 \%$.

The enhancement ratio can also be written $D_{\mathrm{h}}^{-0.6 \pm 0.1}$ which is, given the uncertainties, close to the values proposed by Ishibashi and Nishikawa (1969) $\left(D_{\mathrm{h}}^{-0.67}\right)$ and Aritomi et al. $(1993)\left(D_{\mathrm{h}}^{-0.75}\right)$. It is not clear how Tran et al. (1997), who proposed $D_{\mathrm{h}}^{-1}$ for the confinement effect, established this expression. The range of tested hydraulic diameters, $2.4-2.92 \mathrm{~mm}$, is too small to build a correlation. It is possible, from their articles, that it comes from an analogy with single-phase flow classical theory and has no experimental basis. On the contrary the $D_{\mathrm{h}}^{-0.4}$ term proposed by Steiner and Taborek (1992) is based on some experimental data. Nevertheless the data concerning refrigerant fluids (R11 and R113) were performed for hydraulic diameters from 7 to $20 \mathrm{~mm}$ only. The lowest hydraulic diameters (from 1 to $5 \mathrm{~mm}$ ) were tested with Helium I only so that this $D_{\mathrm{h}}^{-0.4}$ factor is difficult to compare with the present results.

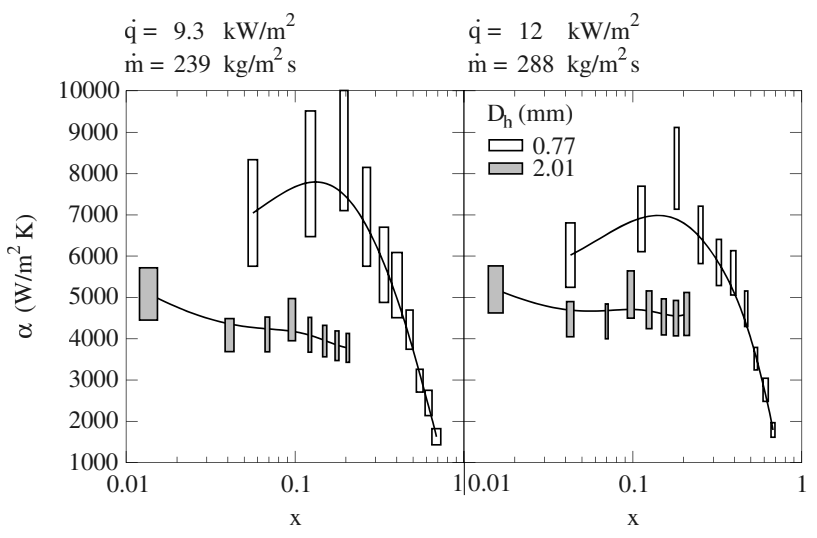

Figure 6: Influence of confinement on heat transfer coefficients.

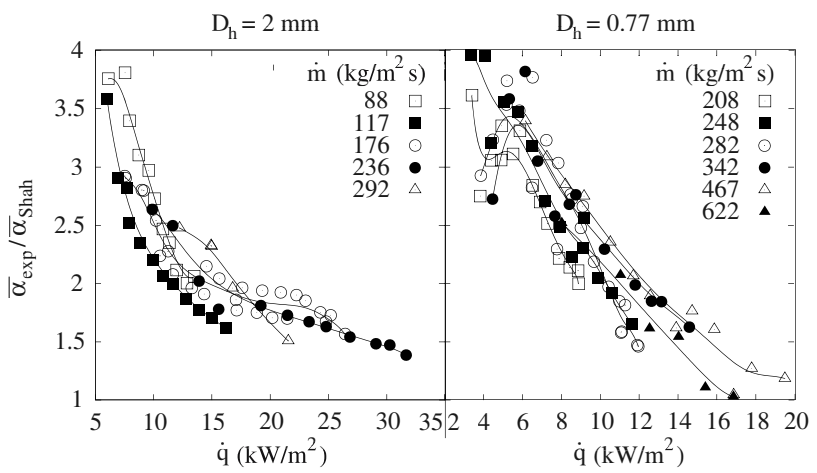

Figure 7: Average heat transfer coefficient versus heat flux.

Figure 7 represents the ratio of the measured average heat transfer coefficient to that predicted by the Shah (1976) correlation for conventional tubes, as a function of the heat flux. This figure shows the global intensification of heat transfer in MPE minichannels compared with conventional tubes. This intensification ranges from 0 to $400 \%$ depending on the heat flux and occurs up to $35 \mathrm{~kW} / \mathrm{m}^{2}$ for $D_{\mathrm{h}}=2 \mathrm{~mm}$ and $20 \mathrm{~kW} / \mathrm{m}^{2}$ for $D_{\mathrm{h}}=0.77 \mathrm{~mm}$. 


\section{Heat transfer analysis}

An analysis and a physical interpretation of these observations will now be proposed. In order to analyse and classify the different heat transfer coefficient behaviours observed on figures 4 and 5 it is useful to represent, for a given vapour quality, the heat transfer coefficient as a function of the heat flux and the heat flux as a function of the wall-fluid temperature difference. For $D_{\mathrm{h}}=2 \mathrm{~mm}$, since Co $<0.5$, the results were analysed in terms of macroscale boiling. This was done on figure 8 , which exhibits two trends:

(i) For $T_{\mathrm{w}}-T_{\mathrm{sat}}<3 \mathrm{~K}$ and $\dot{q}<14 \mathrm{~kW} / \mathrm{m}^{2}, \dot{q}$ is proportional to $T_{\mathrm{w}}-T_{\text {sat }}$. Thus $\alpha$ is independent of $\dot{q}$ and moreover decreases with $\dot{m}$. This region may correspond to a convective boiling regime and, as will be further highlighted, the decrease with $\dot{m}$ may be due to the occurrence of partial dry-out.

(ii) For $T_{\mathrm{w}}-T_{\text {sat }}>3 \mathrm{~K}$ and $\dot{q}>14 \mathrm{~kW} / \mathrm{m}^{2}, \dot{q}$ is proportional to $\left(T_{\mathrm{w}}-T_{\text {sat }}\right)^{3}$, therefore $\alpha$ is proportional to $\dot{q}^{2 / 3}$, and the heat transfer coefficient depends only weakly on $\dot{m}$. This second region may be identified as a nucleate boiling regime.

However, as Co is very close to 0.5 , these results may also be interpreted in terms of microscale boiling with the film evaporation mechanism proposed by Thome et al. (2004).

For $D_{\mathrm{h}}=0.77 \mathrm{~mm} \dot{q}$ is always proportional to $T_{\mathrm{w}}-T_{\text {sat }}$ and $\alpha$ is independent of $\dot{m}$. Since Co is greater than 0.5 , microscale boiling should prevail and according to the three zone model of Thome et al. (2004) film evaporation would be the boiling mechanism occurring in this tube.
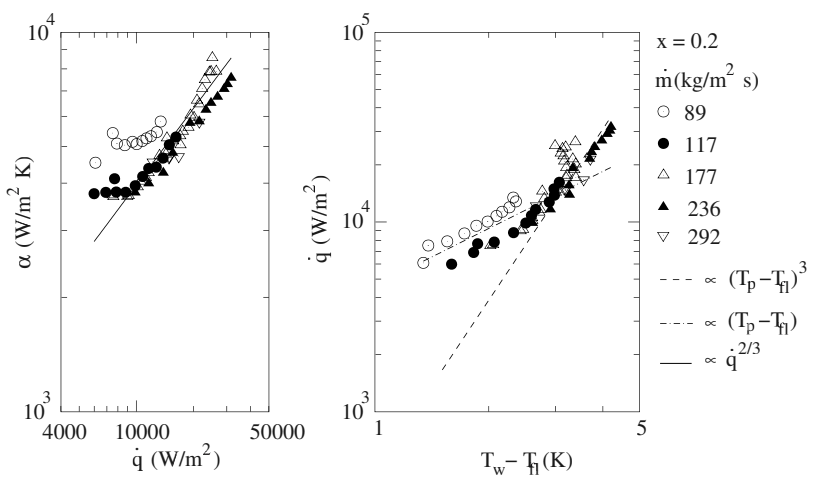

Figure 8: $\alpha$ versus $\dot{q}$ and $\dot{q}$ versus $T_{\mathrm{w}}-T_{\mathrm{sat}}\left(D_{\mathrm{h}}=2 \mathrm{~mm}\right)$.

From an analysis conducted on figures 4 and 5 with the dimensionless boiling number, the following tendencies can be outlined. For $D_{\mathrm{h}}=2 \mathrm{~mm}$ :

(i) for Bo $>4.3 \cdot 10^{-4}$ and $x<0.3-0.4$, the heat transfer coefficient is weakly dependent on $x$ and proportional to $\dot{q}^{2 / 3}$. Thus the nucleate boiling regime might governs this region.

(ii) for Bo $>4.3 \cdot 10^{-4}$ and $x>0.3-0.4$, the heat transfer coefficient decreases with $x$ but is still proportional to $\dot{q}^{2 / 3}$. This suggests that partial dry-out occurs with nucleate boiling which is confirmed on figure 9 where the wall temperature and the statistical uncertainty on $T_{\mathrm{w}}$ suddenly rise for $\mathrm{x}>0.3-0.4$. Most of the data belong to these two regions.

(iii) for Bo $<4.3 \cdot 10^{-4}$ the heat transfer coefficient is weakly dependent on $x$ and proportional to $\dot{q}^{2 / 3}$ for low qualities. It then starts increasing with vapour quality when $x$ is greater than a transition value. This transition value is all the greater since the heat flux is high for a given mass velocity. This behaviour may correspond to competition between a convective boiling and a dry-out regime where partial dry-out and regeneration of the liquid layer occur. Furthermore it was found that this transition occurred for a constant value of the product Bo $\cdot(1-x)$ equal to $2.2 \times 10^{-4}$.

These results are in agreement with the Huo et al. (2004) study which highlighted the prevalence of heat flux dependent boiling and early dry-out in a $2 \mathrm{~mm}$ diameter tube with refrigerant R134a. In their work the boiling number was always greater than $8 \times 10^{-4}$ which is coherent with the present results. 
For $D_{\mathrm{h}}=0.77 \mathrm{~mm}$, Bo is always smaller than $2.2 \cdot 10^{-4}$ and

(i) for $x<0.1-0.2$, the heat transfer coefficient increases weakly with $x$ and is independent of of $\dot{q}$. Film evaporation seems to dominate and the thinning of the liquid layer could explain the increase.

(ii) for $x>0.1-0.2$, the heat transfer coefficient always decreases with $x$ and is still independent of $\dot{q}$. This suggests that intermittent dry-out governs the boiling alongside with film evaporation.

It was found that the critical vapour quality $x_{\mathrm{cr}}$ did not depend on $\dot{q}$ and $\dot{m}$. This does not mean that $x_{\mathrm{cr}}$ does not depend on $\dot{q}$ or $\dot{m}$ but simply that such a variation is less than the uncertainty. The present study highlights a decrease in $x_{\mathrm{cr}}$ from $0.3-0.4$ to $0.1-0.2$ when $D_{\mathrm{h}}$ decreases from 2 to $0.77 \mathrm{~mm}$. For comparison, Huo et al. (2004) found that $x_{\mathrm{cr}}$ decreased from $0.4-0.5$ to $0.2-0.3$ when $D_{\mathrm{h}}$ decreased from 4.26 to $2.01 \mathrm{~mm}$. Given that the uncertainty on $x_{\mathrm{cr}}$ in the present study is about $30 \%$ the results are quite close.

Examination of figure 9 strongly suggest the occurrence of early dry-out. When the liquid layer disappears from the tube wall, the heat transfer coefficient suddenly decreases because of the lesser heat transport properties of the gas. This implies a wall temperature rise since heat removal is less efficient. Moreover, it is well know that dry-out is an intermittent phenomenon and that liquid drops regularly hit the tube wall, so that the tube wall temperature is submitted to quick changes. For the authors this explains why the uncertainty on the tube wall temperature also increases tenfold when dry-out occurs. Furthermore, the occurrence of early dry-out may be explained by the thinning of the liquid layer due to bubbles confinement. This hypothesis also explains why the critical vapour quality decrease from 0.4 to 0.2 when the hydraulic diameter decreases from 2 to $0.77 \mathrm{~mm}$ since this increases bubble confinement. Moreover, this thinning of the liquid layer also explains why the heat transfer coefficient increases when the hydraulic diameter decreases because the heat transfer resistance due to this liquid layer also decreases as long as dry-out does not occur.

The occuring of dry-out may explain why, when combined with heat flux dependent boiling, the heat transfer coefficient decreases with the mass velocity. The greater the mass velocity, the more probable dry-out should be, because the liquid film is increasingly dragged from the wall due to shear stress. Thus dry-out should cause a decrease in the heat transfer coefficient with the mass velocity.

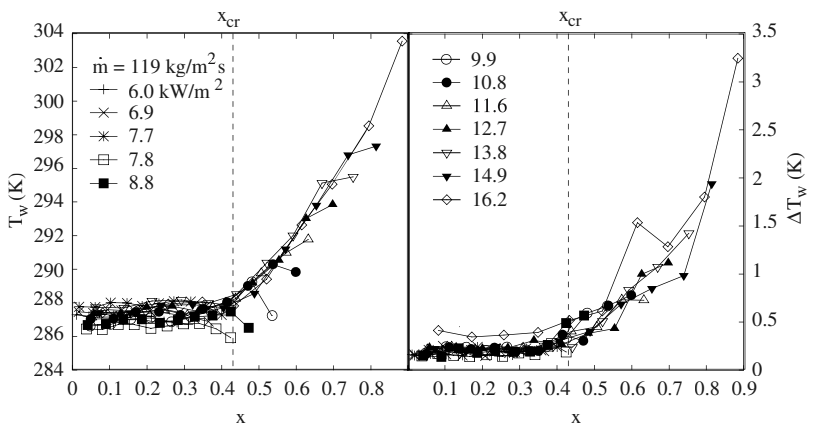

Figure 9: Wall temperature and its uncertainty versus local quality $\left(D_{\mathrm{h}}=2 \mathrm{~mm}\right)$.

To explain why the boiling number seems to govern the transition between heat flux increasing $\alpha$ and vapour quality increasing $\alpha$, the following interpretation is proposed, based on macroscale boiling mechanisms. From the Rohsenow (1952) and Kew and Cornwell (1997) analysis, an inertial characteristic time $\tau_{\mathrm{cv}}$ for the liquid layer and a characteristic time $\tau_{\mathrm{b}}$ for bubbles leaving the wall can be defined. Then, from the Kutaleladze (1981) and Rohsenow (1952) analysis it can be shown that the ratio of these two characteristic times can be written:

$$
\frac{\tau_{\mathrm{cv}}}{\tau_{\mathrm{b}}}=f\left(\theta, g, \rho_{\mathrm{l}}, \rho_{\mathrm{g}}, \sigma\right) \cdot \text { Bo } \cdot f(x) .
$$

This ratio is a comparison of convective effects in the liquid layer (causing $\alpha$ to increase with $x$ ) and bubble dynamics at the wall (causing $\alpha$ to increase with $\dot{q}$ ). Thus $\tau_{\mathrm{cv}} / \tau_{\mathrm{b}}$ is proportional to Bo and a function of vapour quality so that the boiling number is the appropriate dimensionless number to study the transition between these two boiling regimes. 
Finally, figure 10 illustrates the different boiling regimes in minichannels. This work suggests:

(i) when $\mathrm{Bo}>4.3 \cdot 10^{-4}$ and $\mathrm{Co}<0.5$, nucleate boiling and dry-out seems to govern boiling in minichannels. Moreover dry-out occurs at low vapour quality. Most of data for $D_{\mathrm{h}}=2 \mathrm{~mm}$ were in this case.

(ii) when $2.2 \cdot 10^{-4}<\mathrm{Bo}<4.3 \cdot 10^{-4}$ and $\mathrm{Co}<0.5$, nucleate boiling, convective boiling and dry-out seem to compete. The frontier between the nucleate boiling and convective boiling is $\mathrm{Bo} \cdot(1-x)=2.2 \cdot 10^{-4}$. Furthermore dry-out occurs also at low vapour quality and its effects are superimposed on those of nucleate boiling and convective boiling and competes with them.

(iii) when $\mathrm{Bo}<2.2 \cdot 10^{-4}$ and $\mathrm{Co}>0.5$, boiling directly starts in the film evaporation regime with no heat transfer dependance since Bo $\cdot(1-0)=2.2 \cdot 10^{-4}$. The heat transfer coefficient increases with vapour quality, and does not depend upon the mass velocity and heat flux, until dry-out occurs. Then boiling is totally governed by dry-out and the heat transfer coefficient decreases sharply with vapour quality and remains independent of the mass velocity and heat flux.

This scheme illustrates the difference between the classical boiling regimes representations like figures 1 and 2 , and the present results on figure 10 .

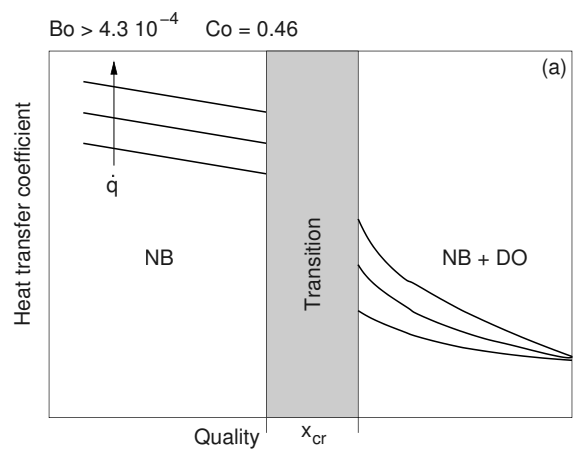

$$
2.210^{-4}<\text { Bo }<4.310^{-4} \quad \text { Co }=0.46
$$
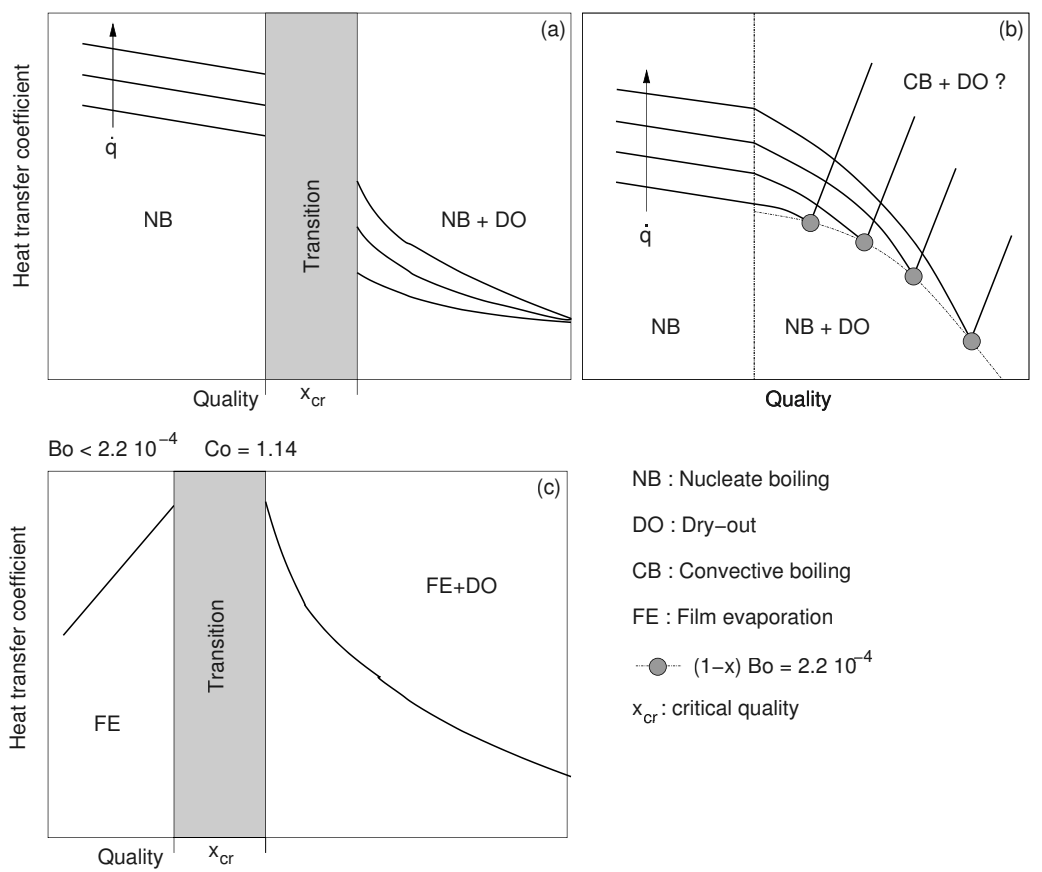

NB : Nucleate boiling

DO : Dry-out

CB : Convective boiling

FE : Film evaporation

(1-x) Bo $=2.210^{-4}$

$\mathrm{x}_{\mathrm{cr}}$ : critical quality

Figure 10: Summing-up of boiling regimes in minichannels observed in the present work.

\section{Correlating data}

Most of the present data points belong to the heat flux dependent regime so that it has been possible to correlate the heat transfer coefficient in this region with $\dot{m}, \dot{q}$ and $x$. Finally, the following expressions were obtained. For $D_{\mathrm{h}}=2 \mathrm{~mm}$ and $\mathrm{Bo}>4.3 \cdot 10^{-4}$,

$$
x<0.3-0.4: \alpha=28 \cdot \dot{q}^{2 / 3} \cdot \dot{m}^{-0.26} \cdot x^{-0.10} \text { and } \quad x>0.3-0.4: \alpha=28 \cdot \dot{q}^{2 / 3} \cdot \dot{m}^{-0.64} \cdot x^{-2.08},
$$

for $D_{\mathrm{h}}=0.77 \mathrm{~mm}$ and $\mathrm{Bo}<2.2 \cdot 10^{-4}$,

$$
x<0.1-0.2: \alpha=10260 \cdot x^{0.15} \text { and } x>0.1-0.2: \alpha=10260 \cdot(1-x)^{1.57} .
$$


Equation (2), obtained by linear least squares fitting over 723 data points, predicts $95 \%$ of our data in the $\pm 30 \%$ range. Equation (3), obtained by linear least squares fitting over 825 data points, predicts $85 \%$ of our data in the $\pm 30 \%$ range.

Figure 11 compares the ability of various correlations to predict the present data for $D_{\mathrm{h}}=2 \mathrm{~mm}$. The analytical expressions of these correlations have been reported in table 4. The Tran et al. (1997) and Kandlikar (2004) correlations, proposed for minichannels predicts the present data rather well in the pure heat flux dependent regime but fails as soon as dry-out occurs. The Steiner and Taborek (1992) correlation over-predicts the present data since it includes a $D_{\mathrm{h}}^{-0.4}$ diameter correction term which is not well fitted for such small diameters. On the contrary the Shah (1976), Liu and Winterton (1991) correlations under-predict the present data because they do not take into account any confinement phenomenon as suggested by Cornwell and Kew (1992, 1995).

The Thome et al. (2004) and Dupont et al. (2004) three zone model was able to predict most of the trends observed, in particular for the $0.77 \mathrm{~mm}$ tube. It is not represented here since it implies the optimization of minimum and maximum liquid layer thickness and bubble generation frequency parameters. However the reader is invited to refer to the cited articles where this model predictions are compared with the present data.

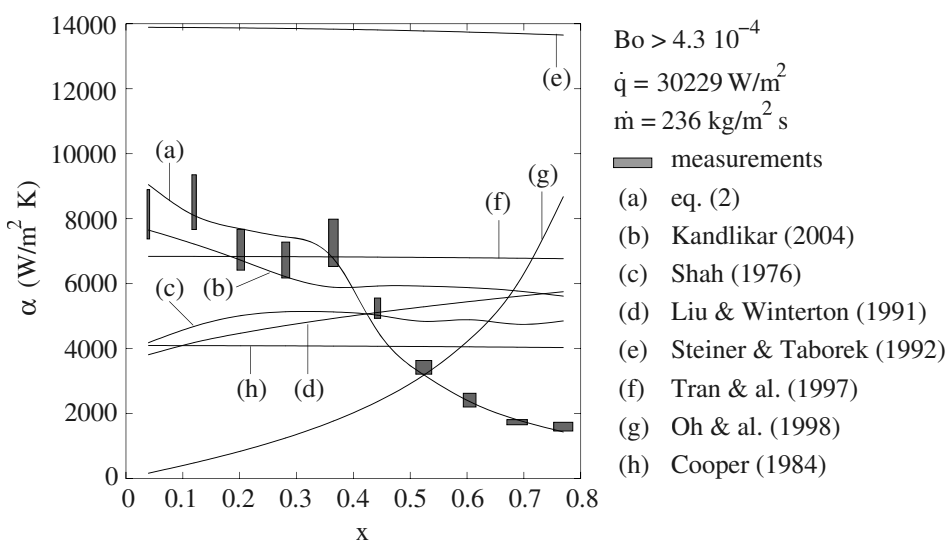

Figure 11: Comparaison with litterature correlations.

Table 4: Expressions of correlations represented on figure 11.

\begin{tabular}{ll}
\hline Author & Expression \\
\hline Shah (1976) & $\alpha_{\mathrm{TP}} / \alpha_{\mathrm{l}}=f(\mathrm{Bo}, \mathrm{Cv})$ \\
Cooper (1984) & $\alpha_{\mathrm{TP}}=55 \cdot p_{\mathrm{r}}^{0,12} \cdot \dot{q}^{2 / 3}\left(-\log _{10} p_{\mathrm{r}}\right)^{-0,55} \tilde{M}^{-0,5}$ \\
Liu and Winterton (1991) & $\alpha_{\mathrm{TP}}^{2}=\alpha_{\mathrm{lo}}^{2}+\alpha_{\mathrm{Cooper}}^{2}$ \\
Steiner and Taborek (1992) & $\alpha_{\mathrm{TP}}^{3}=\alpha_{\mathrm{lo}}^{3}+\alpha_{\mathrm{npb}}^{3}$ \\
Tran et al. (1997) & $N u=770 \cdot\left(\mathrm{Bo} \cdot \mathrm{Re}_{\mathrm{lo}} \cdot \mathrm{Co}\right)^{0,62} \cdot\left(\rho_{\mathrm{v}} / \rho_{\mathrm{l}}\right)^{0,297}$ \\
Oh et al. $(1998)$ & $\alpha_{\mathrm{TP}} / \alpha_{\mathrm{l}}=240 / \chi_{\mathrm{tt}} \cdot\left(1 / \mathrm{Re}{ }_{\mathrm{TP}}\right)^{0,6}$ \\
Kandlikar (2004) & $\alpha_{\mathrm{TP}}=\max \left(\alpha_{\mathrm{nb}}, \alpha_{\mathrm{cb}}\right)$ \\
Present study (2004) & eq. $(2)$ \\
\hline
\end{tabular}

\section{Flow regimes}

Different authors have identified various flow regimes in large channels. In both vertical and horizontal configurations these include bubbly, dispersed bubbly, slug, pseudo-slug, churn, annular, annular mist and dispersed droplet flows. An important difference in minichannels is that the liquid flow is preferentially laminar. Surface tension effects have more and more influence as the hydraulic diameter is reduced. Gravity becomes negligible compared to surface tension so that the orientation is less influential. 
In different studies identifying flow configurations in minichannels, fundamental configurations specific to minichannels are observed: isolated bubbles, confined bubbles and annular slug flow (Kew and Cornwell (1997)). However, some authors observed flow regimes typical of macroscale tubes: bubbly, plug, slug, wavyannular and annular flow (Kuwahara et al. (2000)).

Triplett et al. (1999) measured pressure drop and void fraction in minichannels with air-water adiabatic flows. They observed bubbly, churn, slug, slug-annular and annular flows as in conventional tubes, but the transitions were very different. Moreover they highlighted that the homogeneous model best predicted their pressure drop measurements for every flow configuration except the annular one.

Huo et al. (2004) established a flow map for refrigerant R134a flowing in $2.01 \mathrm{~mm}$ and $4.26 \mathrm{~mm}$ diameter round vertical tubes. They observed six typical flow patterns, i.e. dispersed bubbles, bubbly, slug, churn, annular and mist. Significant differences were found with the existing models for normal size tubes. For example the churn flow pattern becomes a more important flow pattern compared to classical models where it shrinks to a very small area. The authors also observed that reducing the diameter shifted the transition of slug to churn and churn to annular to higher values of the gas velocity. Figure 12 presents the flow map proposed by Huo et al. (2004) for a $2.01 \mathrm{~mm}$ diameter tube. The data of the present work are reported and are all in the annular flow region. As a conclusion, the analysis in terms of flow chart does not allow us to find a clear relation with the heat transfer coefficient measurements.

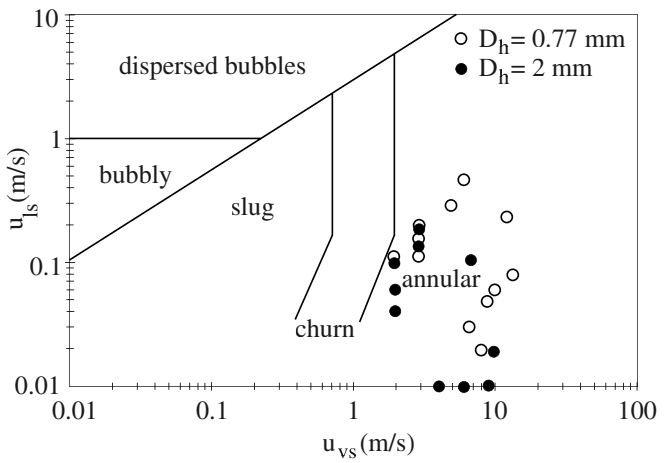

Figure 12: Flow regimes observed by Huo et al. (2004).

\section{Pressure drop}

A time averaging method was used in order to reduce wild pressure oscillations. In order to avoid non uniform distribution of coolant fluid only subcooled liquid entered the inlet manifold. Furthermore the engineering rule that the manifold diameter should be at last five times greater than the channel hydraulic diameter to equalise the fluid distribution was used. However, even if non uniform distribution occurs it will not affect the inlet and outlet measurements which are performed outside of the manifolds and it should not affect the local temperature measurements because of the averaging of wall temperatures across the $N$ channels due to the very high thermal conductivity of the aluminium.

Figure 13 shows the two-phase pressure drop gradient versus the outlet quality. The solid lines represent the pressure gradient modelled with the homogeneous model. As shown in figure 13, the present measured pressure gradient is linear with $x_{0}$. This is characteristic of preponderant frictional pressure losses since integration of the homogeneous model for uniform longitudinal heating, constant thermophysical properties and friction factor shows that the frictional part of the two-phase flow pressure drop is linear with the outlet quality.

However this result and the prevalence of heat flux dependent boiling for $D_{\mathrm{h}}=2 \mathrm{~mm}$ seem contradictory with the prevalence of the annular flow regime (see section 7.) which would rather suggest a separated phases model to calculate pressure losses. Yet, it is well known that the parietal heat transfer deeply disturbs the flow configuration because of the generation of bubbles at the wall. Thus the flow configuration might not be pure annular but actually slug-annular or churn flow. That would promote the mixing of liquid and vapour thus 
explaining the good predictions of the homogeneous model. Nevertheless this issue will be resolved only with a test section allowing flow visualisation and heat transfer at the same time.

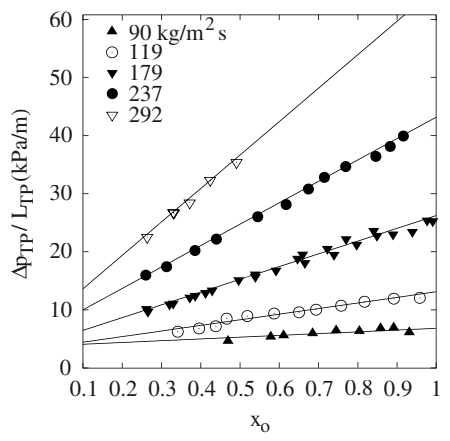

Figure 13: Pressure drop versus outlet quality $\left(D_{\mathrm{h}}=2 \mathrm{~mm}\right)$.

\section{Conclusions}

Forced flow boiling heat transfer in minichannels in similar conditions as encountered in automobile air conditioners has been studied. Higher heat transfer coefficients than in conventional tubes are achieved but dry-out occurs at low vapour qualities thus decreasing performances. However the average heat transfer coefficient remains higher than in conventional tubes. These observations support literature studies which predict that bubble confinement leads to higher heat transfer coefficients and dry-out at low vapour quality in minichannels. The new Kandlikar (2004) general correlation for flow boiling in tubes was found to predict the present results before dry-out occurs. The Thome et al. (2004) and Dupont et al. (2004) three zone model for microscale boiling predicted most of the observed trends, including dry-out and the lack of mass velocity influence. Using it for predictions still requires testing over a consequent database.

The effect of confinement on the heat transfer coefficient before dry-out was found to be an increase of $74 \%$ when the hydraulic diameter decreased from 2 to $0.77 \mathrm{~mm}$. The effect of confinement on dry-out was found to be a decrease in the critical quality from $0.3-0.4$ to $0.1-0.2$ for the same reduction of the hydraulic diameter. Heat flux dependent boiling prevailed in the $2 \mathrm{~mm}$ hydraulic diameter tube while quality dependent boiling prevailed in the 0.77 hydraulic diameter tube because of the difference in boiling and confinement numbers. The transition from one regime to another occurred for Bo $\cdot(1-x) \approx 2.2 \cdot 10^{-4}$ regardless of the heat and mass velocity. Moreover it was found that dry-out could even be the dominant boiling mechanism at low qualities. The results obtained with the $2 \mathrm{~mm}$ hydraulic diameter tube were in total agreement with Huo et al. (2004)'s work. Finally frictional pressure losses seem to dominate up to mass velocities of $469 \mathrm{~kg} / \mathrm{m}^{2} \mathrm{~s}$.

The choice of MPE tubes for the test section allowed easier measurements and results closer to industrial reality. Further studies should put the stress on the accurate influence of channel geometry and confinement on heat transfer with diabatic flow visualisation and a large variety of channels configurations.

\section{Nomenclature}

$$
\begin{aligned}
& A_{\mathrm{fl}} \\
& \mathrm{Bo}=\dot{q} /\left(\dot{m} \cdot h_{\mathrm{lv}}\right) \\
& \mathrm{Co}=\left(\sigma /\left(g \cdot\left(\rho_{\mathrm{l}}-\rho_{\mathrm{v}}\right)\right)^{0.5} / D_{\mathrm{h}}\right. \\
& \mathrm{Cv}=((1-x) / x)^{0.8} \cdot\left(\rho_{\mathrm{v}} / \rho_{\mathrm{l}}\right)^{0.5} \\
& D_{\mathrm{h}}=4 A_{\mathrm{fl}} / P_{\mathrm{fl}} \\
& L \\
& \tilde{M} \\
& \dot{m} \\
& N
\end{aligned}
$$

total flow area

Boiling number

Confinement number

Convection number

hydraulic diameter

tube length

molecular weight

mass velocity

number of channels $\left(\mathrm{m}^{2}\right)$

$\mathrm{g} / \mathrm{mol}$

$\left(\mathrm{kg} / \mathrm{m}^{2} \mathrm{~s}\right)$ 


\begin{tabular}{|c|c|c|}
\hline$P_{\mathrm{fl}}$ & total wet perimeter & (m) \\
\hline$p$ & pressure & $(\mathrm{Pa})$ \\
\hline$p_{\mathrm{r}}$ & reduced pressure & $(\mathrm{Pa})$ \\
\hline$\Delta p$ & pressure loss & $(\mathrm{Pa})$ \\
\hline$\dot{q}$ & heat flux & $\left(\mathrm{W} / \mathrm{m}^{2}\right)$ \\
\hline $\operatorname{Re}=\left(\dot{m} \cdot D_{\mathrm{h}}\right) / \mu_{1}$ & Reynolds number & \\
\hline$T$ & temperature & $(\mathrm{K})$ \\
\hline$v$ & velocity & $(\mathrm{m} / \mathrm{s})$ \\
\hline$x$ & vapour quality & \\
\hline$z$ & z coordinate & $(\mathrm{m})$ \\
\hline \multicolumn{3}{|l|}{ Greek letters } \\
\hline$\alpha$ & heat transfer coefficient & $\left(\mathrm{W} / \mathrm{m}^{2} \mathrm{~K}\right)$ \\
\hline$\chi_{\mathrm{tt}}$ & Lockhart-Martinelli parameter & \\
\hline$\rho$ & mass density & $\left(\mathrm{kg} / \mathrm{m}^{3}\right)$ \\
\hline$\sigma$ & surface tension & $(\mathrm{N} / \mathrm{m})$ \\
\hline$\tau$ & characteristic time & (s) \\
\hline$\theta$ & wetting angle & \\
\hline \multicolumn{3}{|l|}{ Subscripts } \\
\hline $\mathrm{b}$ & bubble & \\
\hline $\mathrm{cv}$ & convective & \\
\hline $\mathrm{fl}$ & fluid & \\
\hline go & all gas flow & \\
\hline i & inlet & \\
\hline $\mathrm{j}$ & joule heated & \\
\hline 1 & liquid & \\
\hline lo & all liquid flow & \\
\hline $\mathrm{nb}$ & nucleate boiling & \\
\hline $\mathrm{npb}$ & nucleate pool boiling & \\
\hline o & outlet & \\
\hline onb & onset of nucleate boiling & \\
\hline sat & saturation & \\
\hline TP & two-phase & \\
\hline $\mathrm{v}$ & vapour & \\
\hline w & wall & \\
\hline
\end{tabular}

\section{References}

B. Agostini. Étude expérimentale de l'ébullition en convection forcée de fluide réfrigérant dans des minicanaux. Ph.D. thesis, Université Joseph Fourier - Grenoble I (2002).

B. Agostini, B. Watel, A. Bontemps, and B. Thonon. "Friction factor and heat transfer coefficient of R134a liquid flow in mini-channels". Applied Thermal Engineering, 22, 16, pp. 1821-1834 (2002).

M. Aritomi, T. Miyata, M. Horiguchi, and S. Sudi. "Thermohydraulics of boiling two-phase flow in high conversion light water reactors (thermohydraulics at low velocities)". International Journal of Multiphase Flow, 19, 1, pp. 51-63 (1993).

D. Brutin, D. Topin, and L. Tadrist. "Experimental study of unsteady convective boiling in heated minichannels". International Journal of Heat and Mass Transfer, 46, pp. 2957-2965 (2003).

J. Collier and J. Thome. Convective boiling and condensation (Oxford University Press, 1994).

M. Cooper. "Saturation nucleate boiling. A simple correlation". $1^{\text {st }}$ U.K. National Conference on Heat Transfer, 2, pp. 785-793 (1984).

K. Cornwell and P. Kew. "Boiling in small parallel channels". In "Proceedings of the International Conference on Energy Efficiency in Process Technology", pp. 624-638 (Elsevier Applied Science, 1992). 
K. Cornwell and P. A. Kew. "Evaporation in micro-channel heat exchangers". In "Proceedings of the th $^{\text {Uh.K. }}$ National Conference on Heat Transfer", pp. 289-294 (ImechE, 1995).

V. Dupont, J. Thome, and A. Jacobi. "Heat transfer model for evaporation in microchannels. part II: comparison with the database". International Journal of Heat and Mass Transfer, 47, pp. 3387-3401 (2004).

A. Feldman. De l'ébullition en convection forcée dans des canaux d'échangeurs à plaques et ailettes. Ph.D. thesis, Université Henry Poincaré, Nancy I (1996).

X. Huo, L. Chen, Y. Tian, and T. Karayiannis. "Flow boiling and flow regimes in small diameter tubes". Applied Thermal Engineering, 24, pp. 1225-1239 (2004).

E. Ishibashi and K. Nishikawa. "Saturated boiling heat transfer in narrow spaces". International Journal of Heat and Mass Transfer, 12, pp. 863-894 (1969).

S. Kandlikar. "Fundamental issues related to flow boiling in minichannels and microchannels". Experimental Thermal Fluid Science, 26, pp. 389-407 (2002).

S. Kandlikar. "An extension of the flow boiling correlation to transition, laminar, and deep laminar flows in minichannels and microchannels". Heat Transfer Engineering, 25, 3, pp. 86-93 (2004).

S. Kandlikar and W. Grande. "Evolution of microchannel flow passages - thermohydraulic performance and fabrication technology". Heat Transfer Engineering, 25, pp. 3-17 (2003).

P. A. Kew and K. Cornwell. "Correlations for the prediction of boiling heat transfer in small diameter channels". Applied Thermal Engineering, 17, 8-10, pp. 705-715 (1997).

S. Kline and F. McClintock. "Describing uncertainties in single-sample experiments". Mechanical Engineering, pp. 3-8 (1953).

S. Kutaleladze. "Principal equations of thermodynamics of nucleate boiling". Heat Transfer Sovietic Research, 13, 3, pp. 1-14 (1981).

K. Kuwahara, S. Koyama, J. Yu, C. Watanabe, and N. Osa. "Flow pattern of pure refrigerant HFC134a evaporating in a horizontal capillary tube". In "Proceedings of Symposium on Energy Engineering in the $21^{\text {th }}$ Century", pp. 445-450 (2000).

Z. Liu and R. Winterton. "A general correlation for saturated and subcooled flow boiling in tubes and annuli, based on a nucleate pool boiling equation". International Journal of Heat and Mass Transfer, 34, 11, pp. 2759-2766 (1991).

H. Oh, M. Katsuta, and K. Shibata. "Heat transfer characteristics of R134a in a capillary tube heat exchanger". In "Proceedings of $11^{\text {th }}$ IHTC", volume 6, pp. 131-136 (1998).

W. Rohsenow. "A method of correlation heat-transfer data for surface boiling of liquids". Transactions of the ASME, 74, pp. 969-976 (1952).

M. Shah. "A new correlation for heat transfer during boiling flow through pipes". Transactions of the ASHRAE, 82, pp. 66-86 (1976).

D. Steiner and J. Taborek. "Flow boiling heat transfer in vertical tubes correlated by an asymptotic model". Heat Transfer Engineering, 13, 2, pp. 43-69 (1992).

J. Thome. "Boiling in microchannels: a review of experiment and theory". International Journal of Heat and Fluid Flow, 25, pp. 128-139 (2004).

J. Thome, V. Dupont, and A. Jacobi. "Heat transfer model for evaporation in microchannels. part I: presentation of the model". International Journal of Heat and Mass Transfer, 47, pp. 3375-3385 (2004).

T. Tran, M. Wambsganss, M. Chyu, and D. France. "A correlation for nucleate flow boiling in small channels". In R. K. Shah, editor, "Compact Heat Exchangers for the Process Industries", pp. 353-363 (Begell House, inc., 1997).

K. Triplett, S. Ghiaasiaan, S. Abdel-Khalik, A. LeMouel, and B. McCord. "Gas liquid two-phase flow in microchannels. Part I : two-phase flow patterns”. International Journal of Multiphase Flow, 25, pp. 377-394 (1999). 